\title{
Effects of concentrate location on the behavior and production of dairy cows milked in a free-traffic automated milking system
}

\author{
A. J. Schwanke, ${ }^{1}$ K. M. Dancy, ${ }^{1}$ T. Didry, ${ }^{1}$ G. B. Penner, ${ }^{2}$ and T. J. DeVries ${ }^{1 *}$ \\ ${ }^{1}$ Department of Animal Biosciences, University of Guelph, Ontario, N1G 2W1, Canada \\ ${ }^{2}$ Department of Animal and Poultry Science, University of Saskatchewan, Saskatoon, SK, S7N 5A8, Canada
}

\begin{abstract}
The objective of this study was to determine whether the amount of concentrate allowance in an automated milking system (AMS) affects partial mixed ration (PMR) sorting behavior, milking activity, and production of lactating dairy cows fed isocaloric diets. Fifteen primiparous Holstein cows were used in a crossover design with 28-d periods, including $14 \mathrm{~d}$ of adaptation and $14 \mathrm{~d}$ of data collection. The cows were housed in a freestall pen with free-traffic access to the AMS. Treatments consisted of a higher-concentrate PMR (HPMR) with a pelleted concentrate allowance of $3.0 \mathrm{~kg} / \mathrm{d}$ on a dry matter (DM) basis in the AMS, or a lowerconcentrate PMR (L-PMR) with a pelleted concentrate allowance of $6.0 \mathrm{~kg} / \mathrm{d}$ in the AMS. As designed, cows on the L-PMR had greater AMS concentrate intake (6.3 vs. $3.1 \mathrm{~kg} / \mathrm{d}$ of DM) compared with the H-PMR. The standard deviation for mean concentrate intake among days increased from 0.38 to $1.0 \mathrm{~kg} / \mathrm{d}$ with greater targeted AMS concentrate intake. When fed the L-PMR diet, PMR intake was reduced compared with when cows were fed the H-PMR diet (17.1 vs. $19.1 \mathrm{~kg} / \mathrm{d}$ of $\mathrm{DM})$. The reduction in PMR intake was compensated for by greater AMS concentrate intake; thus, cows on the L-PMR had greater total dry matter intake (DMI; 23.6 vs. $22.3 \mathrm{~kg} / \mathrm{d})$. Cows sorted against long (>19 $\mathrm{mm})$ and fine $(<4 \mathrm{~mm})$ PMR particle fractions, and in favor of medium ( 8 to $19 \mathrm{~mm}$ ) and short ( 4 to 8 $\mathrm{mm}$ ) PMR fractions when on the H-PMR treatment, but only sorted against the medium and in favor of the short PMR fractions on the L-PMR treatment. PMR eating rate and total time spent eating PMR did not differ significantly between the 2 treatments; however, meal size tended to be larger when cows were fed the H-PMR compared with the L-PMR (2.2 vs. $2.1 \mathrm{~kg}$ $\mathrm{DM} / \mathrm{meal})$. Cows tended to spend $30.8 \mathrm{~min} / \mathrm{d}$ more time lying down when fed the L-PMR. On the L-PMR
\end{abstract}

Received April 5, 2019.

Accepted July 5, 2019.

*Corresponding author: tdevries@uoguelph.ca treatment, cows tended to have more voluntary AMS visits (5.9 vs. 4.6 visits/d), were fetched less (0.1 vs. 0.5 times daily), and had a greater milking frequency (3.5 vs. 3.0 milkings/d) compared with when they were on the H-PMR treatment. However, milk yield was not affected by treatment. These data suggest that allocating a greater proportion of total dietary concentrate to the AMS, in a free-traffic setup, may improve milking activity and decrease the need for fetching, as well as promoting greater amounts of and maintaining consistency in total dry matter consumption.

Key words: robotic milking system, concentrate, partial mixed ration, feeding management

\section{INTRODUCTION}

Automated (robotic) milking systems (AMS) have been used in the dairy industry for over $30 \mathrm{yr}$ (Rossing and Hogewerf, 1997); despite this, research on optimizing feeding strategies within these systems is continuing. Feeding management for AMS herds is different from conventional parlor-milked herds because cows receive supplementary concentrate at the AMS in addition to a partial mixed ration (PMR) at the feed bunk. This concentrate is primarily designed to act as motivation for the cows to voluntarily visit the robot (Prescott et al., 1998; Bava et al., 2012).

Automated milking systems have the advantage that the amount and type of concentrate provided can be customized to each cow, to both minimize fetching and allow for precision feeding (Bach and Cabrera, 2017). Offering greater amounts of concentrate in the AMS creates opportunity to generate voluntary visits, theoretically increasing production and decreasing fetching. However, several challenges have been noted, in providing high levels of concentrate in the AMS, as described by Hare et al. (2018). Factors such as maximum AMS meal size and milking frequency do not guarantee greater concentrate delivery or consumption simply by increasing the amount programmed. Several researchers have reported that cows consistently are delivered and consume less than the maximum amount of con- 
centrate programmed (Halachmi et al., 2005; Bach et al., 2007; Bach and Cabrera, 2017), possibly because the amounts offered per visit exceed the satiety levels of the cow, setting constraints regulating delivery of the concentrate while cows are in the AMS, or because cows are not motivated to visit the AMS frequently enough to be delivered the maximum.

Although some studies have reported that feeding greater quantities of concentrate in the AMS shows a positive effect on milk yield (Halachmi et al., 2005; Henriksen et al., 2018), other evidence indicates that providing greater quantities of concentrate in the AMS does not improve production outcomes, such as total milk yield, component yield, and milking frequency in both free and guided traffic systems (Migliorati et al., 2005; Bach et al., 2007; Henriksen et al., 2019). This is likely due to a substitution effect, whereby greater consumption of supplemental concentrate in the AMS is often accompanied by a decrease in PMR intake. Bach et al. (2007) reported a $1.14 \mathrm{~kg} / \mathrm{d}$ reduction in PMR intake for every $1 \mathrm{~kg} / \mathrm{d}$ of concentrate consumed in a free-traffic AMS. More recently, in a feed-first guidedtraffic barn, Hare et al. (2018) reported a reduction of $1.58 \mathrm{~kg}$ of PMR for every 1-kg increase in concentrate consumed, and Menajovsky et al. (2018) found a 0.78 and $0.89 \mathrm{~kg} / \mathrm{d}$ reduction of PMR for every $1 \mathrm{~kg}$ of concentrate, depending on PMR energy density. Paddick et al. (2019) reported a substitution rate of $0.97 \mathrm{~kg} / \mathrm{d}$ per $1 \mathrm{~kg}$ of concentrate in the AMS. The effects of greater concentrate consumption in the AMS and subsequent PMR substitution rate may also vary due to the energy density of the PMR (Menajovsky et al., 2018). Recent data examining this substitution effect in free-traffic AMS barns is relatively limited compared with data from studies in guided-traffic AMS and, thus, warrants further investigation.

Hare et al. (2018) further suggested that high concentrate provision in the AMS and low concentrate levels in the PMR may encourage cows to selectively consume (sort) the more energy-dense components of the PMR. Extensive sorting of the PMR can drastically alter the composition of the consumed diet, leading to nonuniform consumption relative to formulation (MillerCushon and DeVries, 2017). Cows fed PMR diets lesser in energy density in feed-first guided traffic systems have been shown to sort their PMR to a greater extent compared with cows fed a more energy-dense PMR (Hare et al., 2018; Menajovsky et al., 2018; Paddick et al., 2019). This feeding behavior presents a problem for cows fed a large proportion of their concentrate in the AMS, in that the amount of nutrients actually consumed compared may vary widely from day to day. In addition, greater day-to-day variation in amount of AMS concentrate provided has also been observed with greater concentrate provision at the AMS in feed-first guided-traffic systems (Menajovsky et al., 2018; Paddick et al., 2019). These challenges and data indicate that AMS feeding strategies implemented may make it difficult to target nutrient intakes to optimize health and production outcomes. To our knowledge, only a few studies have evaluated the effects of AMS concentrate provision levels on variation in DMI, as related to PMR sorting and day-to-day variation in AMS concentrate and PMR intake, in free-traffic housing systems.

The objective of this study was to determine how the proportion of total dietary concentrate provision offered in AMS affects the behavior and performance of dairy cows housed in a free-traffic barn. We hypothesized that greater concentrate provision at the AMS would encourage more voluntary milking visits. We also hypothesized that greater concentrate provision at the AMS, and lesser in the PMR, would result in greater sorting of the PMR, and thus prevent cows from achieving their targeted balance of nutrient consumption.

\section{MATERIALS AND METHODS}

\section{Animals and Housing}

Fifteen primiparous lactating Holstein cows were enrolled in the study and housed in a free-traffic AMS pen located at the University of Guelph Livestock Research and Innovation Centre-Dairy Facility (Elora, ON, Canada). At the time of initial treatment assignment, cows were $47.1 \pm 15.0$ (mean \pm standard deviation, SD) DIM, had BW of $592.8 \pm 39.0 \mathrm{~kg}$ and BCS of $3.0 \pm$ 0.16 , produced $34.1 \pm 6.3 \mathrm{~kg} / \mathrm{d}$ of milk, were provided $4.0 \pm 0.8 \mathrm{~kg}$ of $\mathrm{DM} / \mathrm{d}$ of AMS concentrate, and were recorded as eating $15.6 \pm 0.5 \mathrm{~kg}$ of $\mathrm{DM} / \mathrm{d}$ of PMR. All cows had previously been milked twice daily on a rotary milking parlor (DeLaval International, Tumba, Sweden) and ate out of automated feed bins. Before the start of the study, each cow was assigned an individual automated feed bin (Insentec BV, Marknesse, the Netherlands) for the duration of the study. Each cow was trained for a minimum of $7 \mathrm{~d}$ to eat from its own bin, as well as trained for a minimum of $14 \mathrm{~d}$ to access the AMS (DeLaval International VMS). Cows were trained to eat from their own feed bins by guiding each cow to its bin with feed on the day bins were assigned; cows were monitored over the next $6 \mathrm{~d}$ to ensure they only consumed from their assigned bin. Cows attempting to access other bins were redirected to their own bin. By the end of the training period, all cows were successfully trained, as evidenced by exclusive consumption from their own bins. The use of cows and experimental procedures complied with the guidelines of the Canadian Council on Animal Care (2009) and were approved 
by the University of Guelph Animal Care Committee (Animal Use Protocol \#3245).

Within their pen, cows had access to 1 of 15 automated feed bins, 30 lying stalls, 1 cow brush, and 2 water troughs at each end of the pen, which offered ad libitum access to water. The number of cows in the AMS pen included only the 15 cows enrolled in the study. The freestalls were laid out in 2 rows of 15 , tail to tail, and each measured $295 \mathrm{~cm}$ in total length and $127 \mathrm{~cm}$ in width, with the neck rail positioned $188 \mathrm{~cm}$ from the rear curb and $125 \mathrm{~cm}$ above the stall base. The base of the freestalls were mattresses (Pasture Mat; ProMat, Woodstock, ON, Canada) that were bedded with chopped straw. New bedding was added once weekly, and stalls were cleaned and groomed twice daily.

Throughout the duration of the study, milking permission in the AMS was granted when $4 \mathrm{~h}$ had elapsed since the previous milking, or when predicted milk yield exceeded $9.0 \mathrm{~kg}$. The cows had free access to the AMS for $22.5 \mathrm{~h} / \mathrm{d}$, with the remaining time dedicated to 30 min cleaning cycles at 0730,1500 , and $2330 \mathrm{~h}$ daily. To ensure a minimum twice-daily milking frequency, cows that had not voluntarily entered the AMS in more than $10 \mathrm{~h}$ since the previous milking were fetched to be milked at either a morning or evening fetching time (between 0400 and $0530 \mathrm{~h}$ or between 1600 and 1730 $\mathrm{h}$ daily); all fetching activity (including cow number and time, as well as inadvertently fetched cows) was recorded by barn staff.

\section{Study Design and Dietary Treatments}

Sample size and power analyses were used to calculate (as per Morris, 1999) the minimum number of replicates needed per treatment $(\mathrm{n}=15)$ to detect a $10 \%$ level of observed mean difference for the primary outcome variables, including milking frequency, DMI, feed sorting, and milk production. Estimates of variation (average $\mathrm{CV}=13.5 \%$ ) for these variables were based on previously reported values (Hare et al., 2018; Menajovsky et al., 2018; Paddick et al., 2019).

The study was implemented as a crossover design, consisting of 2 dietary treatments and 2, 28-d treatment periods. The first $14 \mathrm{~d}$ (d 1 to 14 ) of each treatment period served as an adaptation period, followed by a 14-d recording period (d 15 to 28). Treatment periods were implemented during the months of May and June 2018. The treatment diets (Table 1) consisted of the following: (1) a lower concentrate allowance in the PMR (L-PMR), with no additional concentrate added to the PMR (Table 2), targeting $6.0 \mathrm{~kg} / \mathrm{d}$ (on a DM basis) of robot concentrate (pellet) in the AMS
(76.3\% of the total diet as PMR and $23.7 \%$ of the total diet as supplemental concentrate in the AMS); and (2) a higher concentrate allowance in the PMR (H-PMR), with an additional $3.0 \mathrm{~kg} / \mathrm{d}$ (on a DM basis) pellet in the PMR (Table 2) provided in the automated feed bin, targeting $3.0 \mathrm{~kg} / \mathrm{d}$ (on a DM basis) of pellet in the AMS (88.2\% of the total diet as PMR and $11.8 \%$ of the total diet as supplemental concentrate in the AMS). For the H-PMR treatment, the additional pellet provided in the PMR was the same as that offered in the AMS. The treatment diets (Table 1), including AMS pellet supplementation, were formulated to meet the nutritional requirements for a $600-\mathrm{kg}$ cow with an expected milk yield of $40 \mathrm{~kg} / \mathrm{d}$, with $4.0 \%$ milk fat and $3.3 \% \mathrm{CP}$ (Cattle Professional, Agricultural Modeling and Training Systems, 2019). These diets were formulated to be equal in macro- and micro-nutrient provision; thus, the sum of the PMR and the pellet offered would provide cows in each treatment with the same total dietary nutrient levels if consumed at the formulated levels.

Initial treatment assignment was balanced for DIM and production level. During the first treatment period, the 7 cows assigned to the L-PMR were $46.7 \pm 5.4$ (mean \pm SD) DIM and producing $33.7 \pm 2.7 \mathrm{~kg} / \mathrm{d}$ of milk at the time of treatment assignment. The 8 cows assigned to the H-PMR diet during the first treatment period were $47.5 \pm 5.9$ DIM and producing $34.4 \pm 2.3$ $\mathrm{kg} / \mathrm{d}$ of milk. Dietary treatments were alternated across feed bins in the pen.

Within each treatment, the eligible daily quantity of pellet available in the AMS was set to exceed the target quantity to ensure that the targeted amount of pellet was achieved. The excess pellet available was adjusted every fourth day during each treatment period, based on the average actual pellet delivery for each cow over the previous $3 \mathrm{~d}$ and corrected for DM content. Therefore, to achieve 3.0 and $6.0 \mathrm{~kg} / \mathrm{d}$ of pellet DM consumption, a total of $3.25 \mathrm{~kg} / \mathrm{d} \mathrm{DM}(3.6 \mathrm{~kg} / \mathrm{d}$ as-fed) and 6.5 $\mathrm{kg} / \mathrm{d} \mathrm{DM}(7.2 \mathrm{~kg} / \mathrm{d}$ as-fed $)$ for each respective treatment was initially eligible. The pellet allocation at each milking was based on a linear accrual over time, with a minimum pellet provision of $50 \mathrm{~g}$ and a maximum of $2.50 \mathrm{~kg}$. Pellet was dispensed at a rate of $0.50 \mathrm{~kg} / \mathrm{min}$. The AMS feeder was calibrated weekly, to ensure that the desired quantity of pellet was dispensed at each AMS visit. To calibrate, the feeder was cleaned, and 4 calibration samples were obtained directly from the feeder. The first sample was discarded, to ensure that any material dislodged during the cleaning process did not affect the calibration outcome. The last 3 samples were weighed, and an average of the 3 weights was entered into the computer system (Delpro 4.5, DeLaval International). 


\section{PMR Feeding Procedure}

The base PMR (with no added AMS pellet) was prepared daily in a TMR mixer wagon (Jaylor Model 5572, Jaylor Fabricating, Orton, ON, Canada) and the

Table 1. Ingredient and chemical composition (mean $\pm \mathrm{SD}$ ) of the treatment $\operatorname{diets}^{1}$

\begin{tabular}{|c|c|c|}
\hline \multirow[b]{2}{*}{ Composition } & \multicolumn{2}{|c|}{ Treatment diets ${ }^{2}$} \\
\hline & L-PMR & H-PMR \\
\hline \multicolumn{3}{|l|}{ Ingredient ( $\%$ of $\mathrm{DM})$} \\
\hline Corn silage $^{3}$ & 27.5 & 27.5 \\
\hline Wheat straw ${ }^{4}$ & 1.5 & 1.5 \\
\hline Alfalfa haylage $^{5}$ & 26.7 & 26.7 \\
\hline High-moisture corn ${ }^{6}$ & 10.3 & 10.3 \\
\hline PMR supplement ${ }^{7}$ & 10.3 & 10.3 \\
\hline Concentrate pellet in $\mathrm{PMR}^{8}$ & - & 11.8 \\
\hline Concentrate pellet in $\mathrm{AMS}^{8}$ & 23.7 & 11.8 \\
\hline \multicolumn{3}{|l|}{ Chemical composition $^{9}$} \\
\hline $\mathrm{DM}(\%)$ & $52.3 \pm 3.1$ & $50.6 \pm 2.4$ \\
\hline $\mathrm{CP}(\%)$ & $16.6 \pm 1.3$ & $16.8 \pm 2.0$ \\
\hline $\mathrm{ADF}(\%$ of $\mathrm{DM})$ & $21.8 \pm 1.3$ & $21.4 \pm 1.3$ \\
\hline $\mathrm{NDF}(\%$ of DM) & $32.7 \pm 1.1$ & $32.6 \pm 1.6$ \\
\hline Starch (\% of DM) & $21.9 \pm 2.1$ & $23.1 \pm 2.5$ \\
\hline $\mathrm{NE}_{\mathrm{L}}(\mathrm{Mcal} / \mathrm{kg}$ of $\mathrm{DM})$ & $1.65 \pm 0.03$ & $1.66 \pm 0.02$ \\
\hline
\end{tabular}

${ }^{1}$ Data are averaged over $14 \mathrm{~d}$ for 15 cows on each treatment.

${ }^{2} \mathrm{~L}-\mathrm{PMR}=$ lower-energy partial mixed ration (PMR) coupled with a high automated milking system (AMS) pellet allowance $(6.0 \mathrm{~kg} / \mathrm{d})$; H-PMR = higher-energy PMR coupled with a low AMS pellet allowance $(3.0 \mathrm{~kg} / \mathrm{d})$.

${ }^{3}$ The DM of corn silage was $39.5 \pm 2.7 \%$ and chemical composition was (DM basis) $8.8 \pm 0.2 \% \mathrm{CP}, 17.0 \pm 2.1 \% \mathrm{ADF}$, and $31.2 \pm 0.5 \% \mathrm{NDF}$.

${ }^{4}$ The DM of straw was $90.8 \pm 1.2 \%$ and chemical composition was (DM basis) $5.6 \pm 0.3 \% \mathrm{CP}, 54.5 \pm 1.0 \% \mathrm{ADF}$, and $78.7 \pm 1.1 \% \mathrm{NDF}$.

${ }^{5}$ The DM of alfalfa haylage was $34.2 \pm 4.1 \%$ and chemical composition was (DM basis) $18.1 \pm 0.8 \% \mathrm{CP}, 33.7 \pm 0.1 \% \mathrm{ADF}$, and $40.6 \pm$ $0.7 \% \mathrm{NDF}$

${ }^{6}$ The DM of high-moisture corn was $75.3 \pm 1.8 \%$ and chemical composition was (DM basis) $9.4 \pm 0.1 \% \mathrm{CP}, 2.4 \pm 0.1 \% \mathrm{ADF}$, and $7.8 \pm$ $0.1 \% \mathrm{NDF}$

${ }^{7}$ The DM of the PMR supplement was $92.2 \pm 0.6 \%$ and chemical composition was (DM basis) $27.4 \pm 0.6 \% \mathrm{CP}, 12.0 \pm 1.0 \% \mathrm{ADF}, 11.4 \pm$ $1.3 \%$ starch, and $23.8 \pm 2.0 \%$ NDF. Supplied by Floradale Feed Mill Ltd. (Floradale, ON, Canada) including ingredients (as fed) $50.0 \%$ Soy Plus (Dairy Nutrition Plus, Ames, IA), $13.0 \%$ wheat shorts, $11.0 \%$ soybean meal, $7.7 \%$ canola, $3.7 \%$ sodium sesquicarbonate, $3.2 \%$ fine salt, $2.5 \%$ limestone calcium carbonate, $2.2 \%$ monocalcium phosphate, $1.7 \%$ Diamond V Yeast XP (Diamond V, Cedar Rapids, IA), 1.1\% magnesium oxide, $1.0 \%$ urea, $1.0 \%$ tallow, $1.0 \%$ EDRC Inorganic Lact PRX (Floradale Feed Mill), 0.7\% Metasmart (Adisseo, Alpharetta, GA), $0.3 \%$ sulfur $99.5 \%$, and $0.04 \%$ Rumensin/Coban (Elanco Animal Health, Greenfield, IN).

${ }^{8}$ The DM of the concentrate pellet was $91.7 \pm 1.3 \%$ and chemical composition was (DM basis) $18.8 \pm 0.8 \% \mathrm{CP}, 14.5 \pm 0.4 \% \mathrm{ADF}, 24.9 \pm$ $0.6 \%$ starch, and $27.6 \pm 0.7 \%$ NDF. Supplied by Floradale Feed Mill Ltd. including ingredients (as fed) $24.2 \%$ wheat shorts, $19.5 \%$ soybean meal, $12.5 \%$ soy hulls (ground), $10.0 \%$ wheat chop (ground wheat), $10.0 \%$ beet pulp, $10.0 \%$ barley chop (ground barley), $5.0 \%$ bakery meal, $5.0 \%$ corn chop (ground corn), 2.0\% molasses (pelleter), $0.8 \%$ limestone calcium carbonate, $0.4 \%$ Pelltech (Borregaard LignoTech, Sarpsborg, Norway), $0.4 \%$ fine salt, $0.2 \%$ magnesium oxide, and $0.1 \%$ FFM Ruminant Micro PRX (Floradale Feed Mill Ltd.).

${ }^{9}$ Values were obtained from chemical analysis of PMR and concentrate samples. $\mathrm{NE}_{\mathrm{L}}$ was calculated based on NRC (2001) equations.
Table 2. Ingredient and chemical composition (mean $\pm \mathrm{SD}$ ) of the treatment partial mixed ration $(\mathrm{PMR})^{1}$

\begin{tabular}{|c|c|c|}
\hline \multirow[b]{2}{*}{ Composition } & \multicolumn{2}{|c|}{ Treatment $\mathrm{PMR}^{2}$} \\
\hline & L-PMR & H-PMR \\
\hline \multicolumn{3}{|l|}{ Ingredient ( $\%$ of $\mathrm{DM})$} \\
\hline Corn silage $^{3}$ & 36.1 & 31.2 \\
\hline Wheat straw $^{4}$ & 2.0 & 1.7 \\
\hline Alfalfa haylage $^{5}$ & 35.0 & 30.3 \\
\hline High-moisture corn ${ }^{6}$ & 13.5 & 11.7 \\
\hline PMR supplement ${ }^{7}$ & 13.5 & 11.7 \\
\hline PMR concentrate pellet ${ }^{8}$ & - & 13.4 \\
\hline \multicolumn{3}{|l|}{ Chemical composition $^{9}$} \\
\hline DM (\%) & $42.3 \pm 3.1$ & $45.5 \pm 2.4$ \\
\hline OM $(\%)$ & $92.2 \pm 0.7$ & $92.9 \pm 0.6$ \\
\hline $\mathrm{CP}(\%)$ & $15.9 \pm 1.1$ & $16.2 \pm 2.1$ \\
\hline $\mathrm{ADF}(\%$ of $\mathrm{DM})$ & $24.0 \pm 1.3$ & $22.0 \pm 1.3$ \\
\hline NDF ( $\%$ of DM) & $34.3 \pm 1.0$ & $32.9 \pm 1.6$ \\
\hline Fat $(\%$ of DM) & $4.2 \pm 0.4$ & $3.4 \pm 0.5$ \\
\hline $\mathrm{NFC}^{10}(\%$ of DM) & $40.8 \pm 2.1$ & $43.2 \pm 1.6$ \\
\hline Starch ( $\%$ of DM) & $20.9 \pm 1.9$ & $23.4 \pm 1.7$ \\
\hline Sugar ( $\%$ of DM) & $2.4 \pm 0.8$ & $2.7 \pm 0.8$ \\
\hline $\mathrm{Ca}(\%$ of $\mathrm{DM})$ & $1.0 \pm 0.1$ & $0.9 \pm 0.1$ \\
\hline $\mathrm{P}(\%$ of $\mathrm{DM})$ & $0.5 \pm 0.04$ & $0.5 \pm 0.03$ \\
\hline $\mathrm{NE}_{\mathrm{L}}(\mathrm{Mcal} / \mathrm{kg}$ of $\mathrm{DM})$ & $1.60 \pm 0.03$ & $1.64 \pm 0.03$ \\
\hline
\end{tabular}

${ }^{1}$ Data are averaged over $14 \mathrm{~d}$ for 15 cows on each treatment.

${ }^{2} \mathrm{~L}-\mathrm{PMR}=$ lower-energy PMR coupled with a high automated milking system (AMS) pellet allowance $(6.0 \mathrm{~kg} / \mathrm{d}) ; \mathrm{H}-\mathrm{PMR}=$ higher-energy PMR coupled with a low AMS pellet allowance $(3.0 \mathrm{~kg} / \mathrm{d})$.

${ }^{3}$ The DM of corn silage was $39.5 \pm 2.7 \%$ and chemical composition was (DM basis) $8.8 \pm 0.2 \% \mathrm{CP}, 17.0 \pm 2.1 \% \mathrm{ADF}$, and $31.2 \pm 0.5 \% \mathrm{NDF}$.

${ }^{4}$ The DM of straw was $90.8 \pm 1.2 \%$ and chemical composition was (DM basis) $5.6 \pm 0.3 \% \mathrm{CP}, 54.5 \pm 1.0 \% \mathrm{ADF}$, and $78.7 \pm 1.1 \% \mathrm{NDF}$.

${ }^{5}$ The DM of alfalfa haylage was $34.2 \pm 4.1 \%$ and chemical composition was (DM basis) $18.1 \pm 0.8 \% \mathrm{CP}, 33.7 \pm 0.1 \% \mathrm{ADF}$, and $40.6 \pm$ $0.7 \% \mathrm{NDF}$.

${ }^{6}$ The DM of high-moisture corn was $75.3 \pm 1.8 \%$ and chemical composition was (DM basis) $9.4 \pm 0.1 \% \mathrm{CP}, 2.4 \pm 0.1 \% \mathrm{ADF}$, and $7.8 \pm$ $0.1 \% \mathrm{NDF}$.

${ }^{7}$ The DM of the PMR supplement was $92.2 \pm 0.6 \%$ and chemical composition was (DM basis) $27.4 \pm 0.6 \% \mathrm{CP}, 12.0 \pm 1.0 \% \mathrm{ADF}$, $11.4 \pm 1.3 \%$ starch, and $23.8 \pm 2.0 \%$ NDF. Supplied by Floradale Feed Mill Ltd. (Floradale, ON, Canada) including ingredients (as fed); $50.0 \%$ Soy Plus (Dairy Nutrition Plus, Ames, IA), $13.0 \%$ wheat shorts, $11.0 \%$ soybean meal, $7.7 \%$ canola, $3.7 \%$ sodium sesquicarbonate, $3.2 \%$ fine salt, $2.5 \%$ limestone calcium carbonate, $2.2 \%$ monocalcium phosphate, 1.7\% Diamond V Yeast XP (Diamond V, Cedar Rapids, IA), $1.1 \%$ magnesium oxide, $1.0 \%$ urea, $1.0 \%$ tallow, 1.0\% EDRC Inorganic Lact PRX (Floradale Feed Mill Ltd.), 0.7\% Metasmart (Adisseo, Alpharetta, GA), $0.3 \%$ sulfur $99.5 \%$, and $0.04 \%$ Rumensin/Coban (Elanco Animal Health, Greenfield, IN).

${ }^{8}$ The DM of the concentrate pellet was $91.7 \pm 1.3 \%$ and chemical composition was (DM basis) $18.8 \pm 0.8 \% \mathrm{CP}, 14.5 \pm 0.4 \% \mathrm{ADF}, 24.9 \pm$ $0.6 \%$ starch, and $27.6 \pm 0.7 \%$ NDF. Supplied by Floradale Feed Mill Ltd. including ingredients (as fed); $24.2 \%$ wheat shorts, $19.5 \%$ soybean meal, $12.5 \%$ soy hulls (ground), $10.0 \%$ wheat chop (ground wheat), $10.0 \%$ beet pulp, $10.0 \%$ barley chop (ground barley), $5.0 \%$ bakery meal, $5.0 \%$ corn chop (ground corn), $2.0 \%$ molasses (pelleter), $0.8 \%$ limestone calcium carbonate, $0.4 \%$ Pelltech (Borregaard LignoTech, Sarpsborg, Norway), $0.4 \%$ fine salt, $0.2 \%$ magnesium oxide, and $0.1 \%$ FFM Ruminant Micro PRX (Floradale Feed Mill Ltd.).

${ }^{9}$ Values were obtained from chemical analysis of PMR samples. $\mathrm{NE}_{\mathrm{L}}$ was calculated based on NRC (2001) equations.

${ }^{10}$ Calculated as $100-[(\% \mathrm{NDF}-\% \mathrm{NDF}-\mathrm{CP})+\% \mathrm{CP}+\%$ Fat $+\%$ Ash)]. 
appropriate amount for each treatment transferred into a feed cart (Super Data Ranger, American Calan, Northwood, NH). For the H-PMR treatment, the additional AMS pellet was weighed out (at amounts described above) and mixed into the base PMR in the feed cart. Treatment diets were mixed daily according to the written standard operating procedures of the research facility.

The PMR was fed once daily between 1030 and 1100 $\mathrm{h}$ into the automated feed bins. The PMR was available ad libitum, and refusals of 5 to $10 \%$ were targeted relative to the amount of feed offered, on an as-fed basis. Actual refusal rate for the duration of the study was $11.3 \pm 7.5 \%$ (mean \pm SD) on a DM basis. Feed was not remixed in the bins during the day. At $1015 \mathrm{~h}$, before each daily feeding, the amounts of refusals were recorded and removed from the bins. The quantity of PMR offered to each cow was adjusted daily based on the average intake over the previous $3 \mathrm{~d}$.

\section{Feeding Behavior}

The automated feed bins continuously measured and recorded the weight of feed at the start and end of each bin visit, as validated by Chapinal et al. (2007), such that PMR feeding time, duration, eating rate, DMI, and meal parameters for each cow could be calculated. The PMR DMI was determined by multiplying the as-fed intake at each bin visit by the weekly average DM percent of the corresponding treatment diet, as determined by DM analysis of fresh PMR samples. Feeding rate for each cow's visit to its bin was calculated as DMI $(\mathrm{kg} / \mathrm{d})$ divided by the total minutes per day spent feeding. These data were then summarized to determine total daily DMI $(\mathrm{kg} / \mathrm{d})$, feeding time $(\mathrm{min} / \mathrm{d})$, and average feeding rate $(\mathrm{kg} / \mathrm{min})$. Meal criteria (the minimum time interval between meals) were determined for each cow in each treatment period, using a software package (MIX 3.1.3; MacDonald and Green, 1988) to fit normal distributions to the frequency of log10-transformed time intervals between bin visits. These criteria were used to combine individual bin visits into meals for each cow, which were then used to analyze meal patterning, as described by DeVries et al. (2003). If an interval of time between 2 bin visits exceeded the determined meal criteria, this indicated a different meal. The number of different meals was classified as meal frequency (no./d). Meal duration (min/meal) was calculated as the time from the start of the first feeding bout until the end of the last feeding bout, at which time the meal criterion was exceeded. Meal size $(\mathrm{kg} / \mathrm{d})$ was calculated as DMI divided by the meal frequency.

\section{Milking Activity, Yield, and Components}

During each treatment period, milking behavior data at every milking were automatically recorded by the AMS software (DelPro 4.5, DeLaval International). These data included milking frequency, duration, milk yield, and refused milkings, which were then used to determine the daily frequency, yield, duration of milking visits, inter-milking interval, and frequency of refused milkings during each treatment period. The fetch sheets were used to identify which milkings for each cow were involuntary. Milk samples from each cow were collected using an automated sampler (DeLaval Robot Sampler; DeLaval International) at every milking of the day on d 20, 24, and 28 of each treatment period. These samples were sent to a DHI testing laboratory (CanWest DHI, Guelph, ON, Canada) for component analysis (fat, CP, SCC, and MUN) using a Fourier-transform infrared full-spectrum analyzer (Milkoscan FT+ and Milkoscan 6000; Foss, Hillerød, Denmark). Fat (\%), CP (\%), SCC (cells $/ \mathrm{mL}$ ), and MUN (mg/dL) values per cow on each sampling day were obtained by calculating the average across milkings, weighted by the milk yield of the sampled milkings.

\section{Behavioral Data Collection}

Standing and lying behavior data were recorded using electronic data loggers (HOBO Pendant G Data Logger, Onset Computer Corporation, Bourne, MA), with leg orientation measurements automatically taken at 1-min intervals, as validated by Ledgerwood et al. (2010). Data loggers were attached to the medial side of the hind leg of each cow using veterinary bandaging tape (Vetrap Bandaging Tape, 3M, London, ON, Canada) on d 14 of each treatment period. On d 22 of each treatment period, a new logger was placed on the other hind leg, before the first logger was removed for data extraction. All loggers were removed after d 28 of each treatment period and data extracted using Onset HOBOware Software (Onset Computer Corporation) before being exported to Microsoft Excel (Microsoft Corporation, Redmond, WA). Microsoft Excel macros (University of British Columbia, 2013) were used to process and summarize lying data as total lying time, frequency of lying bouts, and average bout length (total lying time/frequency of bouts).

An electronic monitoring system (HR-TAG-LD, SCR Engineers Ltd., Netanya, Israel), as validated by Schirmann et al. (2009), was used to continuously monitor rumination activity. A data logger attached to a nylon collar was fitted to each cow $2 \mathrm{~d}$ before the start of the first adaptation period and removed 
at the end of the study period. Data were downloaded from the system at least twice weekly throughout the study. These data, stored in 2-h intervals, were used to determine total time spent ruminating throughout each day for each cow.

\section{Health Data Collection}

Body weight was measured by bringing cows to a scale (1-20W scale, Ohaus, Dundas, ON, Canada) on 2 consecutive days at the start of each adaptation period (d 0 and 1 ), as well as at the start (d 14 and 15) and end (d 27 and 28) of each data collection period, to calculate any changes in BW during the treatment period. Body condition scoring was also conducted by a single assessor on all cows on d 1, 16, and 28 of each treatment period, using the 5-point scale described by Wildman et al. (1982), at 0.25 increments.

Cows received wireless telemetric boluses (eBolus, eCow Ltd., Devon, UK), as validated by Falk et al. (2016), by balling gun $6 \mathrm{~d}$ before the start of the first adaptation period to assess reticulorumen $\mathrm{pH}$. Each bolus took reticulorumen $\mathrm{pH}$ measurements at 15-min intervals, $24 \mathrm{~h} / \mathrm{d}$ for the duration of the study. Data were downloaded from the boluses using a handset and antenna at least twice weekly throughout the study. Downloaded files were then combined into a continuous record for each cow. The data were then summarized by cow and day before determining the daily mean, minimum, and maximum $\mathrm{pH}$ values, $\mathrm{pH}$ range, and time and area spent below the $\mathrm{pH}$ thresholds of 6.0 and 5.8.

\section{Feed Sampling and Analysis}

Throughout the duration of the study, 2 duplicate PMR samples of each of the 2 treatment diets (L-PMR and H-PMR; Table 2) were collected at the time of feed delivery on d 1 and 8 of each adaptation period, as well as on every other day during each treatment data collection period (d 16, 18, 20, 22, 24, 26, and 28). One of the duplicate samples was used to determine DM content and chemical composition, and the other was used to determine particle size distribution (Table 3). Samples of feed refused were also collected from the automated feed bins for each cow on these days, to determine sorting behavior. Samples of each of the PMR components and AMS pellet were taken on d 1, 15, and 28 for DM and nutrient analysis. After collection, all samples were frozen at $-20^{\circ} \mathrm{C}$ until further analysis. Before analysis, all samples were thawed in a refrigerator for at least $24 \mathrm{~h}$.

Each feed sample taken for chemical composition was dried at $55^{\circ} \mathrm{C}$ in an oven for $48 \mathrm{~h}$ to determine DM. The other duplicate fresh feed sample and all refused feed samples were separated by particle size using a 4-screen Penn State Particle Separator (PSPS; Heinrichs, 2013; Maulfair and Heinrichs, 2013) into 4 particle size fractions: long ( $>19 \mathrm{~mm})$, medium $(8$ to $19 \mathrm{~mm})$, short $(4$ to $8 \mathrm{~mm}$ ), and fine $(<4 \mathrm{~mm})$. After being separated into fractions, PSPS samples were oven-dried at $55^{\circ} \mathrm{C}$ for $48 \mathrm{~h}$.

Sorting behavior by individual cows was measured by comparing the particle size distribution of the offered feed to that of the refused feed samples collected for each cow. Sorting of each PSPS fraction was calculated as the actual fraction intake divided by the predicted fraction intake, expressed as a percentage (Leonardi and Armentano, 2003). The actual intake of each fraction was calculated as the amount of the fraction refused subtracted from the amount of the fraction offered (on a DM basis), and the predicted fraction intake was calculated as the DMI of the complete ration multiplied by the percentage of the fraction in the offered ration (on a DM basis). A sorting value of $100 \%$ indicated that no sorting of the fraction occurred (actual intake was equal to predicted intake), whereas a sorting value less than $100 \%$ indicated that sorting occurred against the

Table 3. Particle size distribution and nutrient content by particle size of the fresh experimental diets $(\text { mean } \pm \mathrm{SD})^{1}$

\begin{tabular}{lrr}
\hline & \multicolumn{2}{c}{ Treatment PMR } \\
\cline { 2 - 3 } Item & L-PMR & H-PMR \\
\hline \% DM retained on PSPS screen & $5.3 \pm 2.0$ & $3.6 \pm 1.4$ \\
$\quad$ Long & $50.2 \pm 3.9$ & $51.9 \pm 3.9$ \\
Medium & $17.8 \pm 1.9$ & $16.4 \pm 2.8$ \\
Short & $26.8 \pm 3.9$ & $28.1 \pm 4.0$ \\
Fine & & \\
ADF (\% of PSPS screen DM) & \\
Long & $32.3 \pm 2.6$ & $30.7 \pm 3.2$ \\
Medium & $27.3 \pm 1.6$ & $24.0 \pm 0.9$ \\
Short & $20.9 \pm 2.3$ & $19.9 \pm 1.6$ \\
Fine & $14.0 \pm 1.5$ & $14.9 \pm 0.9$ \\
NDF (\% of PSPS screen DM) & & \\
Long & $45.4 \pm 1.7$ & $43.5 \pm 1.7$ \\
Medium & $37.3 \pm 1.8$ & $36.5 \pm 1.2$ \\
Short & $32.0 \pm 2.4$ & $31.4 \pm 1.8$ \\
Fine & $23.0 \pm 1.9$ & $24.1 \pm 2.0$ \\
Starch (\% of PSPS screen DM) ${ }^{3}$ & & \\
Long & $14.0 \pm 3.7$ & $17.8 \pm 2.1$ \\
Medium & $21.0 \pm 2.5$ & $23.8 \pm 2.1$ \\
Short & $27.1 \pm 5.3$ & $28.1 \pm 2.9$ \\
Fine & $31.3 \pm 3.3$ & $30.0 \pm 5.0$ \\
\hline
\end{tabular}

${ }^{1}$ Particle size determined by processing feed samples with the Penn State Particle Separator (PSPS), which has a 19-mm screen (long), an 8-mm screen (medium), a 4-mm screen (short), and a pan (fine). Data are averaged over $14 \mathrm{~d}$ for 15 cows on each treatment.

${ }^{2} \mathrm{~L}-\mathrm{PMR}=$ lower-energy partial mixed ration $(\mathrm{PMR})$ coupled with a high automated milking system (AMS) pellet allowance $(6.0 \mathrm{~kg} / \mathrm{d})$; H-PMR = higher-energy PMR coupled with a low AMS pellet allowance $(3.0 \mathrm{~kg} / \mathrm{d})$.

${ }^{3}$ Values were obtained from chemical analysis of TMR samples separated by particle size with the PSPS. 
fraction (actual intake was less than predicted intake), and a sorting value greater than $100 \%$ indicated that sorting occurred in favor of the fraction (actual intake was greater than predicted intake).

After being dried, the feed components, fresh PMR samples, and fresh PSPS fraction samples of the treatment PMR diets were ground through a 1-mm sieve (Model 4 Wiley Laboratory Mill, Thomas Scientific, Swedesboro, NJ). Ground samples were then pooled by sample type and date, and shipped to A\&L Canada Laboratories Inc. (London, ON, Canada) for analysis of $\mathrm{DM}\left(60^{\circ} \mathrm{C}\right.$; AOAC International, 2000, method 934.01), CP (combustion; AOAC International, 2000, method 990.03; Leco FP-628 Nitrogen Analyzer, Leco, St. Joseph, MI), OM $\left(550^{\circ} \mathrm{C}\right.$; AOAC International, 2000, method 942.05; Blue M Electric programmable asher, Blue M, Watertown, WI), ADF (AOAC International, 2000, method 973.18; Ankom 200 Fiber Analyzer, Ankom Technology, Macedon, NY), NDF with amylase and sodium sulfite (AOAC International, 2000, method 2002.04; Ankom 200, Ankom Technology), and starch with heat-stable amylase and amyloglucosidase (AOAC International, 2000, method 996.11, K-TSTA Total Starch Assay Procedure, Megazyme, Wicklow, Ireland).

\section{Statistical Analyses}

All statistical analyses were conducted using SAS 9.4 software (SAS Institute Inc., 2013). All values reported are least squares means. Significance was declared if $P \leq 0.05$, and tendencies were reported if $0.05<P$ $\leq 0.10$. Before analyses, all data were screened for normality using the UNIVARIATE procedure of SAS. The assumptions of normality were met for all variables except SCC data, and duration and area reticulorumen $\mathrm{pH}$ were below 5.8 and 6.0 , which were all transformed by taking the natural logarithm. The means and SED reported for the transformed $\mathrm{pH}$ variables were generated before transformation. Due to a technical error with the milk sampler during the first treatment period, those data were analyzed based on 2 sampling days rather than the intended 3 .

Data for DMI, feeding behavior, sorting, reticulorumen $\mathrm{pH}$, rumination, lying behavior, milking activity, and production were analyzed using the MIXED procedure of SAS, treating day within cow as a repeated measure. The model included the fixed effects of period, treatment, day, period $\times$ treatment interaction, and day $\times$ treatment interaction, and the random effect of cow. The variance-covariance matrix structure used was autoregressive, chosen on the basis of best fit according to Schwarz's Bayesian information criterion. Degrees of freedom for fixed effects were estimated using the Kenward-Roger option in the MODEL statement. To test whether sorting of the diets occurred, sorting activity for each particle fraction was tested within treatment, using the above-mentioned model, for a difference from 100 using $t$-tests.

To determine day-to-day variation in DM consumption of robot pellet and PMR, and total feed consumption, the standard deviation in intake across each 14-d observation period was generated for each of these variables. These data did not have equal variance and, thus, were analyzed using the GLIMMIX procedure of SAS to account for unequal variance, with treatment, period, and period $\times$ treatment as fixed effects, and the random effect of cow. Cow BW and BCS data were analyzed using the MIXED procedure of SAS, with treatment, period, and period $\times$ treatment as fixed effects, and the random effect of cow.

\section{RESULTS}

When cows were fed the H-PMR treatment, they had a $2.0 \mathrm{~kg} / \mathrm{d}$ greater PMR intake than when fed the L-PMR (Table 4; Figure 1a). As designed by the treatments, H-PMR cows had lesser daily AMS pellet delivery (Table 4) on a DM basis. As a result, cows fed the H-PMR treatment consumed $1.3 \mathrm{~kg} / \mathrm{d}$ less total DMI. The standard deviation for the mean concentrate provision among days increased with greater targeted AMS concentrate provision, whereas the standard deviation for mean PMR intake and total DMI did not vary between treatments. No differences in PMR feeding time (Table 4; Figure 1b), feeding rate (Table 4; Figure 1c), meal criteria, meal frequency, meal duration, total daily meal time, interval between meals, or within-meal interval were observed between the treatments (Table 4). Cows on the H-PMR tended to have larger PMR meals and tended to spend $30.8 \mathrm{~min} / \mathrm{d}$ less time lying down, compared with cows on the L-PMR. We found no differences between treatments in the duration of time spent ruminating, frequency of lying bouts per day, or lying bout length.

When cows were fed the H-PMR treatment, they sorted against long $(>19 \mathrm{~mm})$ and fine $(<4 \mathrm{~mm})$ PMR particles, but when fed the L-PMR treatment, they did not sort these particles (Table 5). On the H-PMR, cows sorted for medium-length $(<19,>8 \mathrm{~mm})$ particles, whereas on the L-PMR they sorted against these particles. Cows on both treatments sorted for short $(<8$, $>4 \mathrm{~mm}$ ) particles; however, on the L-PMR, cows sorted for these particles to a greater extent than when fed the H-PMR. We detected no differences between treatments for BW, BCS, or measures of reticulorumen $\mathrm{pH}$ (Table 6).

When fed the L-PMR treatment, cows had a greater milking frequency $(+0.5$ milkings/d; Table 7; Figure 
2a, b), $2.6 \mathrm{~min} / \mathrm{d}$ more daily box time, and fewer fetches per day, and were delivered $0.8 \mathrm{~kg}$ more pellet per milking (Table 7). When cows were fed L-PMR, they tended to have 1.3 more total AMS visits daily (Table 7; Figure 2c) and tended to spend $69.4 \mathrm{~min}$ less time between milkings (Table 7). No differences were detected between treatments in the frequency of rejected milkings per day, daily yield, yield per milking, box time per visit, milk fat or protein, MUN, or SCC.

\section{DISCUSSION}

Concentrates are often used as motivation to encourage cows to voluntarily visit the AMS (Prescott et al., 1998; Bava et al., 2012); however, little is known about how levels of concentrate allocation at the AMS, versus in the PMR, affect PMR feeding behavior. Hare et al. (2018) suggested that higher levels of concentrate consumption in a guided-traffic AMS would encourage cows to sort their PMR more extensively. Therefore, we were interested in determining how concentrate location affects PMR feeding behavior, as well as overall feeding behavior, milking activity, and production for dairy cows milked in a free-traffic AMS.

On each treatment in this study, cows reached, on average, their target daily AMS concentrate allocation of 3.0 and $6.0 \mathrm{~kg}$ of DM for the H-PMR and L-PMR treatments, respectively. In contrast, studies comparing different amounts of concentrate allowance in the AMS (Halachmi et al., 2005; Migliorati et al., 2005; Bach et al., 2007; Henriksen et al., 2019) all reported that one or both of the high- or low-allowance treatment groups did not meet their targeted AMS concentrate allocation. To ensure that our targets were met, the maximum daily allowance was programmed to exceed the target, a strategy that was also successfully used by Hare et al. (2018), Menajovsky et al. (2018), and Paddick et al. (2019). The increased day-to-day variation in concentrate allocation observed in the L-PMR treatment was similar to that reported by Menajovsky et al. (2018) and Paddick et al. (2019), but, interestingly, day-to-day variation in total DMI did not differ between treatments, suggesting that cows were able to maintain overall daily consistency in their total DMI. The variation in daily AMS concentrate intake, however, may have resulted in day-to-day variation in the composition of the total DMI consumed.

On the L-PMR treatment, cows consumed less PMR than when fed the H-PMR treatment, with the increase in PMR intake on the H-PMR observed throughout the day. However, given the difference in pellet provided at the AMS, cows consumed more total DM on the L-PMR treatment. These results support the idea that increasing AMS concentrate allocation acts as

Table 4. Effect of dietary treatments on DMI, feeding behavior, rumination, and lying behavior ${ }^{1}$

\begin{tabular}{|c|c|c|c|c|}
\hline \multirow[b]{2}{*}{ Item } & \multicolumn{2}{|c|}{ Dietary treatment ${ }^{2}$} & \multirow[b]{2}{*}{ SEM } & \multirow[b]{2}{*}{$P$-value } \\
\hline & L-PMR & H-PMR & & \\
\hline \multicolumn{5}{|l|}{ DMI $(\mathrm{kg} / \mathrm{d})$} \\
\hline PMR & 17.1 & 19.1 & 0.42 & 0.001 \\
\hline AMS pellet & 6.3 & 3.1 & 0.04 & $<0.001$ \\
\hline Total & 23.6 & 22.3 & 0.40 & 0.03 \\
\hline \multicolumn{5}{|c|}{ Standard deviation in intake $(\mathrm{kg} / \mathrm{d})$} \\
\hline PMR & 1.46 & 1.60 & 0.11 & 0.40 \\
\hline AMS pellet & 1.00 & 0.38 & 0.07 & $<0.001$ \\
\hline Total & 1.74 & 1.68 & 0.11 & 0.71 \\
\hline \multicolumn{5}{|l|}{ PMR feeding behavior } \\
\hline Feeding time $(\mathrm{min} / \mathrm{d})$ & 198 & 201 & 8.80 & 0.81 \\
\hline Feeding rate $(\mathrm{kg} / \mathrm{min})$ & 0.1 & 0.1 & 0.01 & 0.35 \\
\hline Meal criterion (min) & 33 & 34 & 3.43 & 0.90 \\
\hline Meal frequency (meals/d) & 8.8 & 8.8 & 0.20 & 0.77 \\
\hline Meal size $(\mathrm{kg}$ of $\mathrm{DM} / \mathrm{meal})$ & 2.1 & 2.2 & 0.06 & 0.06 \\
\hline Meal duration ( $\mathrm{min} / \mathrm{meal})$ & 35 & 34 & 1.43 & 0.47 \\
\hline Total daily meal time $(\mathrm{min} / \mathrm{d})$ & 288 & 287 & 6.59 & 0.91 \\
\hline Interval between meals ( $\mathrm{min}$ ) & 136 & 134 & 2.95 & 0.55 \\
\hline Within-meal interval (min) & 91 & 87 & 6.12 & 0.65 \\
\hline Rumination (min/d) & 562 & 552 & 7.10 & 0.36 \\
\hline Lying bouts (no./d) & 9.5 & 9.8 & 0.46 & 0.65 \\
\hline Lying time $(\mathrm{min} / \mathrm{d})$ & 704 & 673 & 12.33 & 0.08 \\
\hline Lying bout length ( $\mathrm{min} /$ bout) & 81 & 76 & 3.50 & 0.27 \\
\hline
\end{tabular}


a partial substitute for PMR consumption. However, compared with the PMR substitution effect of 1.14 $\mathrm{kg} / \mathrm{d}$ DMI reduction per 1-kg increase of AMS concentrate consumption observed by Bach et al. (2007) in a free-traffic AMS, we only observed a substitution rate of $0.63 \mathrm{~kg} / \mathrm{d}$ per $1 \mathrm{~kg}$ of AMS concentrate. Similarly, our observed substitution effect was less than that seen in feed-first guided-traffic systems, with Hare et al. (2018), Menajovsky et al. (2018), and Paddick et al. (2019) reporting substitution rates of $1.58,0.78$ to 0.89 ,
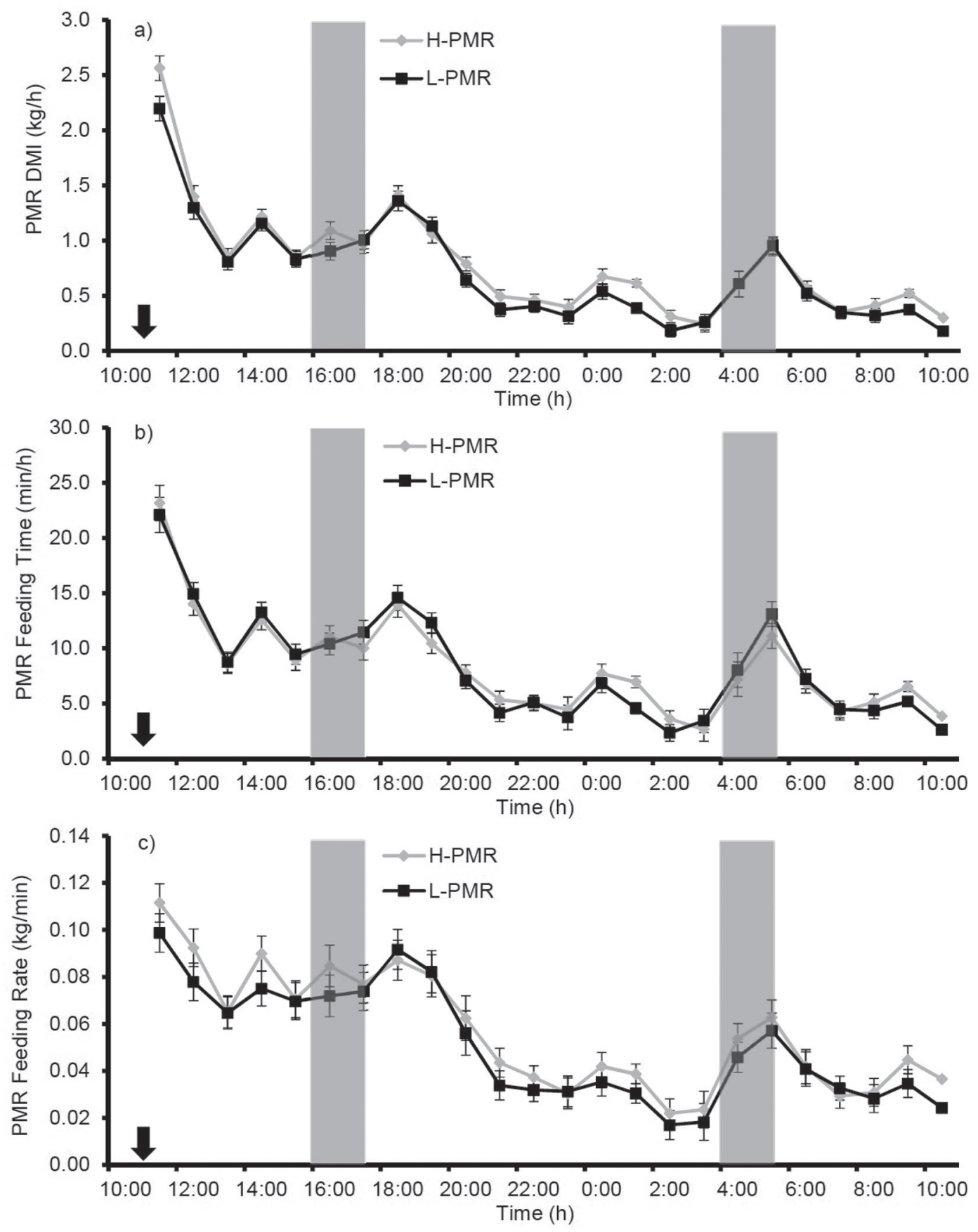

Figure 1. Hourly mean \pm SE: (a) partial mixed ration (PMR) DMI, (b) PMR feeding time, and (c) PMR feeding rate of primiparous lactating dairy cows on (1) H-PMR = higher-energy PMR coupled with a low automated milking system (AMS) pellet allowance (3.0 kg/d) or (2) L-PMR = lower-energy PMR coupled with a high AMS pellet allowance $(6.0 \mathrm{~kg} / \mathrm{d})$. Cows were fed once daily at $1100 \mathrm{~h}$ (arrows), and data were averaged over $14 \mathrm{~d}$ for 15 cows on each treatment. Fetching activity occurred between 0400 and 0530 h or between 1600 and 1730 h daily (gray shading). 
Table 5. Effect of dietary treatments on the sorting (\%) of long, medium, short, and fine particles within the partial mixed ration $(\mathrm{PMR})^{1}$

\begin{tabular}{|c|c|c|c|c|}
\hline \multirow[b]{2}{*}{ Sorting of particle fractions (\%) } & \multicolumn{2}{|c|}{ Dietary treatment ${ }^{2}$} & \multirow[b]{2}{*}{ SEM } & \multirow[b]{2}{*}{$P$-value } \\
\hline & L-PMR & H-PMR & & \\
\hline Long & 98.6 & $94.8^{*}$ & 1.23 & 0.03 \\
\hline Medium & $99.3^{*}$ & $101.4^{*}$ & 0.17 & $<0.001$ \\
\hline Short & $101.5^{*}$ & $100.8^{*}$ & 0.25 & 0.04 \\
\hline Fine & 100.7 & $97.7^{*}$ & 0.41 & $<0.001$ \\
\hline
\end{tabular}

${ }^{1}$ Sorting $\%=100 \times(\mathrm{n} \mathrm{DMI} / \mathrm{n}$ predicted $\mathrm{DMI})$, where $\mathrm{n}=$ particle fraction (long, medium, short, or fine). Sorting values equal to $100 \%$ indicate no sorting, $<100 \%$ indicate selective refusals (sorting against), and $>100 \%$ indicate preferential consumption (sorting for). Data are averaged over $14 \mathrm{~d}$ for 15 cows on each treatment. Difference in individual sorting values (within treatment) from $100 \%$ expressed as: ${ }^{*} P<0.05$; all other values are $P>0.05$. Particle size determined by Penn State Particle Separator, with a 19-mm screen (long), an 8-mm screen (medium), a 4-mm screen (short), and a pan (fine). Data are averaged over $14 \mathrm{~d}$ for 15 cows on each treatment.

${ }^{2} \mathrm{~L}-\mathrm{PMR}=$ lower-energy PMR coupled with a high automated milking system (AMS) pellet allowance (6.0 $\mathrm{kg} / \mathrm{d}) ; \mathrm{H}-\mathrm{PMR}=$ higher-energy PMR coupled with a low AMS pellet allowance $(3.0 \mathrm{~kg} / \mathrm{d})$.

and $0.97 \mathrm{~kg} / \mathrm{d}$ of PMR per $1 \mathrm{~kg}$ of AMS concentrate, respectively. In cows with similar DIM to those in the present study, Henriksen et al. (2019) observed PMR substitution rates of $1.14 \mathrm{~kg} / \mathrm{d}$ per $1 \mathrm{~kg}$ of AMS concentrate consumed, and $1.08 \mathrm{~kg} / \mathrm{d}$ per $1 \mathrm{~kg}$ of AMS concentrate offered. The difference between those and the current study may be due to physiological status of the cows or to the difference in AMS concentrate provision between treatments. Bach et al. (2007), Hare et al. (2018), and Henriksen et al. (2019) all used data from both primiparous and multiparous cows, compared with only primiparous in the present study. Researchers have demonstrated that primiparous cows have a lower DMI than multiparous cows (Beauchemin et al., 2002; Azizi et al., 2009; DeVries et al., 2011), which may have a limiting effect on the substitution rate observed in first-lactation cows. In addition, we used cows that were in early to peak lactation, whereas the cows in previous studies were in mid-lactation. Therefore, it is possible that rumen fill was a factor limiting DMI in mid-lactation cows (Allen et al., 2009). In the present study, even though NDF content of the L-PMR was high, that likely did not limit intake of that PMR. The intake of NDF as a percent of BW on L-PMR was

Table 6. Effect of dietary treatments on BW, BCS, and measures of reticulorumen $\mathrm{pH}^{1}$

\begin{tabular}{|c|c|c|c|c|}
\hline \multirow[b]{2}{*}{ Item } & \multicolumn{2}{|c|}{ Dietary treatment ${ }^{2}$} & \multirow[b]{2}{*}{ SEM } & \multirow[b]{2}{*}{$P$-value } \\
\hline & L-PMR & H-PMR & & \\
\hline BW (kg) & 608.9 & 616.4 & 11.58 & 0.65 \\
\hline $\mathrm{BCS}$ & 2.98 & 2.98 & 0.04 & 0.93 \\
\hline \multicolumn{5}{|c|}{ Reticulorumen $\mathrm{pH}$} \\
\hline Mean & 5.89 & 5.91 & 0.05 & 0.75 \\
\hline Maximum & 6.27 & 6.29 & 0.04 & 0.76 \\
\hline Minimum & 5.54 & 5.55 & 0.05 & 0.85 \\
\hline \multicolumn{5}{|c|}{ Duration $(\mathrm{min} / \mathrm{d})$} \\
\hline$<6.0$ & 924 & 838 & 98.19 & 0.38 \\
\hline$<5.8$ & 593 & 468 & 90.84 & 0.80 \\
\hline \multicolumn{5}{|c|}{ Area $(\mathrm{pH} \times \min / \mathrm{d})$} \\
\hline$<6.0$ & 288 & 235 & 50.21 & 0.84 \\
\hline$<5.8$ & 133 & 103 & 32.40 & 0.53 \\
\hline \multicolumn{5}{|c|}{ Acidosis index $(\mathrm{pH} \times \min / \mathrm{kg}$ of $\mathrm{PMR})$} \\
\hline$<6.0$ & 18 & 13 & 2.93 & 0.59 \\
\hline$<5.8$ & 8 & 6 & 1.89 & 0.31 \\
\hline \multicolumn{5}{|c|}{ Acidosis index $(\mathrm{pH} \times \min / \mathrm{kg}$ of total intake $)$} \\
\hline$<6.0$ & 13 & 11 & 2.28 & 0.80 \\
\hline$<5.8$ & 6 & 5 & 1.47 & 0.44 \\
\hline
\end{tabular}

${ }^{1}$ Data are averaged over $14 \mathrm{~d}$ for 15 cows on each treatment.

${ }^{2} \mathrm{~L}-\mathrm{PMR}=$ lower-energy partial mixed ration (PMR) coupled with a high automated milking system (AMS) pellet allowance $(6.0 \mathrm{~kg} / \mathrm{d}) ; \mathrm{H}-\mathrm{PMR}=$ higher-energy PMR coupled with a low AMS pellet allowance $(3.0$ $\mathrm{kg} / \mathrm{d})$. 
Table 7. Effect of dietary treatments on milking behavior and production ${ }^{1}$

\begin{tabular}{|c|c|c|c|c|}
\hline \multirow[b]{2}{*}{ Item } & \multicolumn{2}{|c|}{ Dietary treatment ${ }^{2}$} & \multirow[b]{2}{*}{ SEM } & \multirow[b]{2}{*}{$P$-value } \\
\hline & L-PMR & H-PMR & & \\
\hline \multicolumn{5}{|l|}{ Milking activity $^{1}$} \\
\hline Milking frequency (no./d) & 3.53 & 3.03 & 0.12 & 0.003 \\
\hline Fetches (no./d) & 0.143 & 0.513 & 0.09 & 0.004 \\
\hline AMS visits (no./d) & 5.89 & 4.62 & 0.51 & 0.08 \\
\hline Rejected milkings (no./d) & 2.36 & 1.59 & 0.41 & 0.19 \\
\hline Pellet intake per milking (kg of DM/milking) & 1.87 & 1.10 & 0.06 & $<0.001$ \\
\hline Inter-milking interval (min) & 449 & 519 & 28.81 & 0.10 \\
\hline Box-time (min/milking) & 6 & 7 & 0.29 & 0.53 \\
\hline Daily box-time $(\min / \mathrm{d})$ & 22 & 19 & 0.65 & 0.01 \\
\hline Milk yield $^{1}(\mathrm{~kg} / \mathrm{d})$ & 40.6 & 39.1 & 0.74 & 0.13 \\
\hline Milk yield per milking ${ }^{1}$ (kg/milking) & 12.1 & 13.9 & 0.76 & 0.11 \\
\hline \multicolumn{5}{|l|}{ Milk composition ${ }^{3}(\%)$} \\
\hline Fat & 3.29 & 3.42 & 0.10 & 0.35 \\
\hline Protein & 2.96 & 2.97 & 0.05 & 0.92 \\
\hline \multicolumn{5}{|l|}{ Milk component yield ${ }^{3}(\mathrm{~kg} / \mathrm{d})$} \\
\hline Fat & 1.30 & 1.32 & 0.05 & 0.80 \\
\hline Protein & 1.18 & 1.15 & 0.04 & 0.59 \\
\hline $\operatorname{MUN}^{3}(\mathrm{mg} / \mathrm{dL})$ & 11.1 & 11.8 & 0.32 & 0.14 \\
\hline Natural log-transformed $\mathrm{SCC}^{4}$ & 10.7 & 10.4 & 0.27 & 0.49 \\
\hline $\mathrm{SCC}^{5}(\times 1,000$ cells $/ \mathrm{mL})$ & 44.7 & 34.1 & - & - \\
\hline \multicolumn{5}{|c|}{${ }^{1}$ Data are averaged over $14 \mathrm{~d}$ for 15 cows on each treatment. } \\
\hline \multicolumn{5}{|c|}{$\begin{array}{l}{ }^{2} \mathrm{~L}-\mathrm{PMR}=\text { lower-energy partial mixed ration }(\mathrm{PMR}) \text { coupled with a high automated milking system (AMS) } \\
\text { pellet allowance }(6.0 \mathrm{~kg} / \mathrm{d}) ; \mathrm{H}-\mathrm{PMR}=\text { higher-energy PMR coupled with a low AMS pellet allowance }(3.0 \\
\mathrm{kg} / \mathrm{d}) .\end{array}$} \\
\hline
\end{tabular}

$0.96 \%$ for the PMR, which is less than $1.1 \%$, the level at which intake may become compromised for cows in early lactation (McCarthy et al., 2015).

Another factor contributing to the difference in substitution rates seen between our study and previous work could be that the difference in AMS concentrate intake between our treatment groups was $3.2 \mathrm{~kg} / \mathrm{d}$, whereas differences of 4.0 to $4.5 \mathrm{~kg} / \mathrm{d}$ were tested in previous studies (Bach et al., 2007; Hare et al., 2018; Menajovsky et al., 2018). More accurate substitution rates could be obtained by using actual AMS concentrate consumption values, rather than values of concentrate offered (Henriksen et al., 2019). The daily milk yields reported by Bach et al. $(2007 ; 32.5 \mathrm{~kg} / \mathrm{d})$ and Hare et al. $(2018 ; 36 \mathrm{~kg} / \mathrm{d})$ were also less than those found in the present study $(40 \mathrm{~kg} / \mathrm{d})$. However, as in the current study, Paddick et al. (2019) observed a similar milk yield of $37.4 \mathrm{~kg} / \mathrm{d}$ using early-lactation heifers and treatments that differed in AMS concentrate by 1.5 $\mathrm{kg} / \mathrm{d}$. Thus, it is unclear to what degree physiological status and nutrient demand may also affect response to greater concentrate allowance in the AMS.

When cows were on the L-PMR treatment, they visited the AMS more often, had a greater milking frequency throughout the day (resulting in a shorter intermilking interval), and required fewer fetches per day than when on the H-PMR treatment. These results provide support for the suggestion that greater quantities of concentrate in the AMS may be a stronger motivator in free-traffic systems than in guided systems, as AMS concentrate feeding levels have not previously been found to affect milking visits in guided-traffic systems (Migliorati et al., 2005; Hare et. al., 2018; Menajovsky et. al., 2018). Bach et al. (2007) reported that greater concentrate provision in a free-traffic AMS did not affect milking frequency. However, when those researchers separately analyzed the data from cows that were fetched, they reported that greater AMS concentrate levels may have increased the milking frequency of cows that did not need to be fetched but did not reduce the need to fetch cows that would not otherwise visit the AMS. Henriksen et al. (2018) observed numerically higher milk yields of $0.4 \mathrm{~kg} / \mathrm{d}$ and $0.7 \mathrm{~kg} / \mathrm{d}$ with greater AMS concentrate levels, but no corresponding change in AMS visits in a free-traffic system. A more recent study found no effect of AMS concentrate intake levels on milk yield or AMS visits in a free-traffic system (Henriksen et al., 2019). The effect on voluntary milking visits in the present study may also explain why cows on the H-PMR treatment tended to spend 30.8 $\mathrm{min} / \mathrm{d}$ less time lying down than did those on L-PMR. Cows that were fetched more times per day would have 

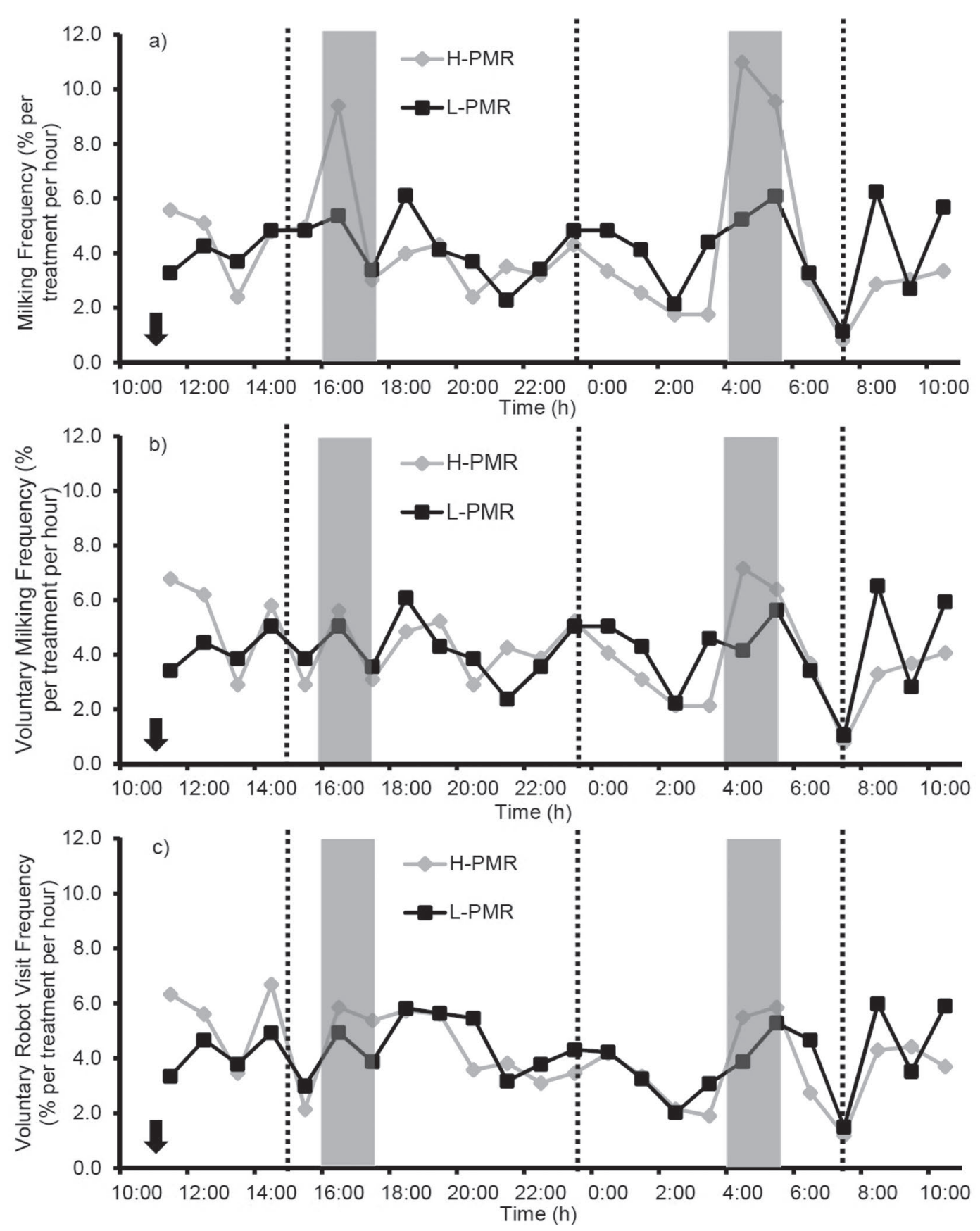

Figure 2. Hourly average: (a) relative milking frequency, (b) relative voluntary milking frequency, and (c) relative voluntary robot visit frequency of primiparous lactating dairy cows on (1) H-PMR = higher-energy partial mixed ration (PMR) coupled with a low automated milking system (AMS) pellet allowance $(3.0 \mathrm{~kg} / \mathrm{d})$ or $(2) \mathrm{L}-\mathrm{PMR}=$ lower-energy PMR coupled with a high AMS pellet allowance (6.0 kg/d). Cows were fed once daily at $1100 \mathrm{~h}$ (arrows), and data were averaged over $14 \mathrm{~d}$ for 15 cows on each treatment. Fetching activity occurred between 0400 and $0530 \mathrm{~h}$ or between 1600 and $1730 \mathrm{~h}$ daily (gray shading). Cleaning of AMS occurred at 0730, 1500, and $2330 \mathrm{~h}$ daily (dotted lines).

spent more time standing in the holding area, when they would otherwise likely be lying down. To our knowledge, no other research has documented any effect of AMS concentrate provision on lying duration in free-traffic AMS barns.
Contrary to the findings of Hare et al. (2018), Paddick et al. (2019), and our own hypothesis, cows on the H-PMR treatment sorted their PMR diet to a greater extent than did the cows on the L-PMR treatment. This is congruent with previous studies showing that 
TMR diets with lower forage:concentrate ratios are sorted more than those with higher forage:concentrate ratios (DeVries et al., 2007, 2008). When fed the HPMR treatment, cows sorted against the longest PMR particles, but they did not sort those particles on LPMR. Differences in sorting between the treatments in the present study are likely attributable to H-PMR having a lower forage content than L-PMR, and thus a decreased proportion of long particles and increased proportion of short and fine particles, which may make that diet easier to sort (Miller-Cushon and DeVries, 2017). Several researchers have demonstrated that cows normally sort against medium particles and for fine particles (DeVries et al., 2007; Hosseinkhani et al., 2008); however, the cows on the H-PMR treatment in the present study sorted for medium particles and against fine particles. This is likely because the cows were sorting for the additional robot pellet that made up part of the medium particle fraction, as evidenced by the higher starch content of the medium fraction of the H-PMR treatment. The fine particles may have been sorted against on the H-PMR because they contained proportionately more NDF than in the L-PMR treatment.

The sorting results of the present study likely differ from those of other AMS studies on the effect of concentrate allocation due to differences in the particle distribution of the PMR diets used. Hare et al. (2018) reported that cows fed higher levels of concentrate in the AMS sorted to a greater extent for medium particles and against fine particles. However, the PMR diets used in that study had a greater proportion of long and short particles and a lower proportion of medium and fine particles, compared with the present study. Our treatment diets had a particle size distribution similar to that recommended for conventionally fed TMR (Heinrichs, 2013). Similar to Hare et al. (2018), Menajovsky et al. (2018) found that cows fed lower amounts of concentrate in the AMS sorted against medium particles; however, their PMR diets contained a lower proportion of medium and fine particles and a higher proportion of short particles compared with the present study.

Despite more PMR sorting when cows were on the H-PMR in the present study, cows did not change their rate of intake or meal duration on that treatment. This is surprising, as the increased sorting activity exhibited by cows on the H-PMR treatment would be expected to decrease their rate of consumption (Hare et al., 2018; Paddick et al., 2019). It is possible that the greater proportion and lesser sorting of long particles observed when cows were on the L-PMR treatment promoted more chewing and, thus, a slower-than-expected eating rate.
Yield per milking was $1.8 \mathrm{~kg}$ greater when cows were on the H-PMR treatment and, although not significantly different, daily milk yield was numerically 1.5 $\mathrm{kg} / \mathrm{d}$ less compared with cows on the L-PMR treatment. The differences in yield per milking and daily milk yield between the treatments is likely due to the greater inter-milking interval and lower frequency of milking (3.0 vs. 3.5 milkings/d), a response that has been documented in numerous studies (Soberon et al., 2011; Bortacki et al., 2017; Bogucki, 2018), as well as the lesser total DMI (22.3 vs. $23.6 \mathrm{~kg} / \mathrm{d}$ ), which would have decreased the nutrients available for milk production. The observed $1.5 \mathrm{~kg} / \mathrm{d}$ numerical difference in milk yield between treatments was an increase of only $3.8 \%$; based on our sample size and observed variation in milk production, our study had sufficient power to detect a difference of $5.2 \%$.

As the amount of pellet dispensed in the robot does not guarantee consumption (Henriksen et al., 2019), this study was limited by the ability to measure only the effects of concentrate provided in the AMS. We conducted random observations of the pellet feeder in the AMS after cows left following milking. From those observations it was determined that the amount of uneaten pellet was not significant; thus, concentrate consumed in the AMS was assumed to be equal to the amount delivered. Refused AMS concentrate left during previous AMS visits may have been consumed by cows subsequently visiting the AMS. Given that both treatments were imposed at the same time within the pen, it may be assumed that the risk of consuming leftover AMS concentrate would have been equal between treatments and, thus, not had a significant effect on the overall treatment response. Despite this, more opportunities should be sought in future research to measure the amount of concentrate consumed in the AMS unit instead of the proportion allocated within the AMS.

It should be noted that in the present study the AMS was only servicing 15 cows, which is markedly below the typical capacity of these units (approximately 50 to 60 cows per AMS). Previous similar studies also operated below the recommended cow per AMS ratio at approximately 30 to 40 cows per AMS (Hare et. al., 2018; Menajovsky et al., 2018; Paddick et al., 2019). Additionally, the pen stocking density of these previous studies was $67 \%$ (cows:stalls), and in the present study it was 50\%. Henriksen et al. (2019) reported groups varying between 47 and 65 cows per AMS, and Bach et al. (2007) reported groups of approximately 57 cows per AMS and 2 cows per feeding place. Thus, cows in the present study did not experience the same level of competition or traffic in their pen or at the AMS, as would typically be seen in a commercial setting. However, based on the box times observed in this study, we 
can predict that increasing the number of animals to a density of 50 to 60 cows per AMS would result in box times of 18 to $22 \mathrm{~h} / \mathrm{d}$ for the L-PMR treatment and 16 to $19 \mathrm{~h} / \mathrm{d}$ for the H-PMR treatment. Thus, allocating more concentrate to the AMS may still be a valid strategy in higher-stocked situations, based on the box times we observed, without limiting access to the AMS or milk yield per AMS. It would be beneficial to verify this prediction in a future study, using the present treatments in a situation with greater AMS stocking density.

\section{CONCLUSIONS}

For primiparous cows in early to peak lactation and milked in a free-traffic AMS with low stocking density, allocating a greater quantity of concentrate to the AMS and altering the PMR to maintain total dietary nutrient density decreased the extent of PMR sorting and increased total DMI, despite lower PMR intake. Further, allocating a greater proportion of dietary concentrate to the AMS also increased voluntary AMS visits and milkings and reduced the frequency of fetching to the AMS. Despite greater day-to-day variation in AMS concentrate intake, allocating a greater amount of concentrate to the AMS resulted in decreased sorting of the PMR, with no difference in day-to-day variation of PMR intake and total DMI. Therefore, offering a greater proportion of total dietary concentrate at the AMS in free-traffic systems with low stocking density may promote greater milking activity while maintaining consistency in total amount of DM consumed.

\section{ACKNOWLEDGMENTS}

We thank the staff of the University of Guelph, Livestock Research and Innovation Centre-Dairy Facility (Elora, ON, Canada) for their assistance during the project, as well as Keshia Paddick (Lakeland College, $\mathrm{AB}$, Canada) for her assistance programming AMS concentrate delivery. This project was financially supported by a Natural Sciences and Engineering Research Council of Canada (NSERC; Ottawa, ON, Canada) Discovery Grant. Further, equipment for this project was supported through contributions from the Canadian Foundation for Innovation (CFI; Ottawa, ON, Canada) and the Ontario Research Fund (Toronto, ON, Canada).

\section{REFERENCES}

Agricultural Modeling and Training Systems LLC. 2019. Cattle Professional. Groton, NY.

Allen, M. S., B. J. Bradford, and M. Oba. 2009. The hepatic oxidation theory of the control of feed intake and its application to ruminants. J. Anim. Sci. 87:3317-3334. https://doi.org/10.2527/ jas. 2009-1779

AOAC International. 2000. Official Methods of Analysis. 17th ed. AOAC International, Gaithersburg, MD.

Azizi, O., O. Kaufmann, and L. Hasselmann. 2009. Relationship between feeding behaviour and feed intake of dairy cows depending on their parity and milk yield. Livest. Sci. 122:156-161. https:// doi.org/10.1016/j.livsci.2008.08.009.

Bach, A., and V. Cabrera. 2017. Robotic milking: Feeding strategies and economic returns. J. Dairy Sci. 100:7720-7728. https://doi .org/10.3168/jds.2016-11694.

Bach, A., C. Iglesias, S. Calsamiglia, and M. Devant. 2007. Effect of amount of concentrate offered in automatic milking systems on milking frequency, feeding behaviour, and milk production of dairy cattle consuming high amounts of corn silage. J. Dairy Sci. 90:5049-5055. https://doi.org/10.3168/jds.2007-0347.

Bava, L., A. Tamburini, C. Penati, E. Riva, G. Mattachini, G. Provolo, and A. Sandrucci. 2012. Effects of feeding frequency and environmental conditions on dry matter intake, milk yield and behaviour of dairy cows milked in conventional or automatic milking systems. Ital. J. Anim. Sci. 11:230-235. https://doi.org/10.4081/ijas.2012 .e42.

Beauchemin, K. A., M. Maekawa, and D. A. Christensen. 2002. Effect of diet and parity on meal patterns of lactating dairy cows. Can. J. Anim. Sci. 82:215-223. https://doi.org/10.4141/a01-080.

Bogucki, M. 2018. Effect of lactation stage and milking frequency on milk yield from udder quarters of cows. S. Afr. J. Anim. Sci 48:636-642. https://doi.org/10.4314/sajas.v48i4.5.

Bortacki, P., R. Kujawiak, E. Czerniawska-Piatkowska, S. S. Kirdar, J. Wóscik, and W. Grzesiak. 2017. Impact of milking frequency on yield, chemical composition and quality of milk in high producing dairy herd. Mljekarstvo 67:226-230. https://doi.org/10.15567/ mljekarstvo.2017.0307.

Chapinal, N., D. M. Veira, D. M. Weary, and M. A. G. von Keyserlingk. 2007. Technical note: Validation of a system for monitoring individual feeding and drinking behaviour and intake in grouphoused dairy cows. J. Dairy Sci. 90:5732-5736. https://doi.org/10 $.3168 /$ jds.2007-0331.

DeVries, T. J., K. A. Beauchemin, and M. A. G. von Keyserlingk. 2007. Dietary forage concentration affects the feed sorting behavior of lactating dairy cows. J. Dairy Sci. 90:5572-5579.

DeVries, T. J., F. Dohme, and K. A. Beauchemin. 2008. Repeated ruminal acidosis challenges in lactating dairy cows at high and low risk for developing acidosis: Feed sorting. J. Dairy Sci. 91:3958 3967. https://doi.org/10.3168/jds.2008-1347.

DeVries, T. J., L. Holtshausen, M. Oba, and K. Beauchemin. 2011. Effect of parity and stage of lactation on feed sorting behavior of lactating dairy cows. J. Dairy Sci. 94:4039-4045. https://doi.org/ 10.3168/jds.2011-4264.

DeVries, T. J., M. A. G. von Keyserlingk, D. M. Weary, and K. A. Beauchemin. 2003. Technical note: Validation of a system for monitoring feeding behavior of dairy cows. J. Dairy Sci. 86:3571-3574. https://doi.org/10.3168/jds.S0022-0302(03)73962-9.

Falk, M., A. Münger, and F. Dohme-Meier. 2016. Technical note: A comparison of reticular and ruminal $\mathrm{pH}$ monitored continuously with 2 measurement systems at different weeks of early lactation. J. Dairy Sci. 99:1951-1955. https://doi.org/10.3168/jds.2015-9725.

Halachmi, I., S. Ofir, and J. Miron. 2005. Comparing two concentrate allowances in an automatic milking system. Anim. Sci. 80:339-343. https://doi.org/10.1079/ASC40480339.

Hare, K., T. J. DeVries, K. S. Schwartkopf-Genswein, and G. B. Penner. 2018. Does the location of concentrate provision affect voluntary visits, and milk component yield for cows in an automated milking system? Can. J. Anim. Sci. 98:399-404. https://doi .org/10.1139/cjas-2017-0123.

Heinrichs, A. J. 2013. The Penn State Particle Separator. Extension publication DSE 2013-186. Pennsylvania State University, College Park, PA.

Henriksen, J. C. S., L. Munksgaard, and M. R. Weisbjerg. 2018 Short-term responses in production and behavior during periods 
of change in concentrate allowance for dairy cows. J. Dairy Sci. 101:7942-7953. https://doi.org/10.3168/jds.2018-14624.

Henriksen, J. C. S., M. R. Weisbjerg, P. Løvendahl, T. Kristensen, and L. Munksgaard. 2019. Effects of an individual cow concentrate strategy on production and behavior. J. Dairy Sci. 102:2155-2172. https://doi.org/10.3168/jds.2018-15477.

Hosseinkhani, A., T. J. DeVries, K. L. Proudfoot, R. Valizadeh, D. M. Veira, and M. A. G. von Keyserlingk. 2008. The effects of feed bunk competition on the feed sorting behavior of close-up dry cows. J. Dairy Sci. 91:1115-1121.

Ledgerwood, D. N., C. Winckler, and C. B. Tucker. 2010. Evaluation of data loggers, sampling intervals, and editing techniques for measuring the lying behavior of dairy cattle. J. Dairy Sci. 93:51295139. https://doi.org/10.3168/jds.2009-2945.

Leonardi, C., and L. E. Armentano. 2003. Effect of quantity, quality, and length of alfalfa hay on selective consumption by dairy cows. J. Dairy Sci. 86:557-564. https://doi.org/10.3168/jds.S0022 -0302(03)73634-0.

MacDonald, P. D. M., and P. E. J. Green. 1988. User's Guide to Program MIX: An Interactive Program for Fitting Mixtures of Distributions. Release 2.3, January 1988. Ichthus Data Systems, Hamilton, ON, Canada.

Maulfair, D. D., and A. J. Heinrichs. 2013. Effects of varying forage particle size and fermentable carbohydrates on feed sorting, ruminal fermentation, and milk and component yields of dairy cows. J. Dairy Sci. 96:3085-3097. https://doi.org/10.3168/jds.2012-6048.

McCarthy, M. M., H. Dann, and T. R. Overton. 2015. Feeding the fresh cow. Pages 171-183 in Proc. Cornell Nutr. Conf. Feed Manuf. Cornell University, Ithaca, NY.

Menajovsky, S. B., C. E. Walpole, T. J. DeVries, K. S. SchwartzkopfGenswein, M. E. Walpole, and G. B. Penner. 2018. The effect of the forage-to-concentrate ratio of the partial mixed ration (PMR) and the quantity of concentrate in an automatic milking system (AMS) for lactating Holstein cows. J. Dairy Sci. 101:9941-9953. https://doi.org/10.3168/jds.2018-14665.

Migliorati, L., M. Speroni, S. Lolli, and F. Calza. 2005. Effect of concentrate feeding on milking frequency and milk yield in an automatic milking system. Ital. J. Anim. Sci. 4:221-223. https://doi .org/10.4081/ijas.2005.2s.221.

Miller-Cushon, E. K., and T. J. DeVries. 2017. Feed sorting in dairy cattle: Causes, consequences, and management. J. Dairy Sci. 100:4172-4183. https://doi.org/10.3168/jds.2016-11983.
Morris, T. R. 1999. Experimental Design and Analysis in Animal Sciences. CABI Publishing, New York, NY.

National Research Council. 2001. Nutrient Requirements of Dairy Cattle. 7th rev. ed. Natl. Acad. Sci., Washington, DC.

Paddick, K. S., T. J. DeVries, K. Schwartzkopf-Genswein, M. A. Steele, M. E. Walpole, and G. B. Penner. 2019. Effect of the amount of concentrate offered in an automated milking system on milk yield, milk composition, ruminal digestion, and behavior of primiparous Holstein cows fed isocaloric diets. J. Dairy Sci. 102:2173-2187. https://doi.org/10.3168/jds.2018-15138.

Prescott, N. B., T. T. Mottram, and A. J. F. Webster. 1998. Relative motivations of dairy cows to be milked or fed in a Y-maze and an automatic milking system. Appl. Anim. Behav. Sci. 57:23-33. https://doi.org/10.1016/S0168-1591(97)00112-3.

Rossing, W., and P. H. Hogewerf. 1997. State of the art of automatic milking systems. Comput. Electron. Agric. 17:1-17. https://doi .org/10.1016/S0168-1699(96)01229-X.

Salfer, J., and M. Endres. 2014. How are robotic milking dairies feeding their cows? Pages 77-80 in Proc. 4-State Dairy Nutrition Conference, Dubuque, IA. Wisconsin Agri-Business Association, Madison

SAS Institute Inc. 2013. SAS Version 9.4. SAS Institute Inc., Cary, NC.

Schirmann, K., M. A. G. von Keyserlingk, D. M. Weary, D. M. Veira, and W. Heuwieser. 2009. Technical note: Validation of a system for monitoring rumination in dairy cows. J. Dairy Sci. 92:6052-6055. https://doi.org/10.3168/jds.2009-2361.

Soberon, F., C. Ryan, D. Nydam, D. Galton, and T. Overton. 2011. The effects of increased milking frequency during early lactation on milk yield and milk composition on commercial dairy farms. J. Dairy Sci. 94:4398-4405. https://doi.org/10.3168/jds.2010-3640.

University of British Columbia. 2013. UBC Animal Welfare Program: SOP-HOBO Data Loggers. Pages 1-23. University of British Columbia, Vancouver, Canada.

Wildman, E. E., G. M. Jones, P. E. Wagner, and R. L. Bowman. 1982. A dairy cow body condition scoring system and its relationship to selected production characteristics. J. Dairy Sci. 65:495-501. https://doi.org/10.3168/jds.S0022-0302(82)82223-6. 